\title{
Analysis of the Relationship between Responsible Supply Chain Management and Social Performance
}

\author{
Maxwell Opuni Antwi ${ }^{1}$, Lulin Zhou ${ }^{1}$, Charles Kwarteng Antwi, ${ }^{2}$ \\ ${ }^{1}$ School of Management, Jiangsu University, 301 Xuefu Road, Zhenjiang, Jiangsu Province, P.R.C \\ ${ }^{2}$ Scuola Mattei, ENI Corporate University, Milan, Italy \\ Corresponding Author: Maxwell Opuni Antwi (maxwellopuni@gmail.com)
}

\begin{abstract}
Responsible supply chain management (RSCM) as a growing sub-field of supply chain management (SCM) has gathered increasing consideration from both practitioners and academics for the past two decades. Even though manufacturing firms have implemented RSCM behaviors throughout this period, there exist some concerns as to whether these RSCM behaviors are being applied for the effect they have on social performance outcomes. In recent times, various debates have been opened concerning this RSCM paradox, throwing doubt on whether an investment in the implementation of RSCM behaviors certainly comes with a corresponding social and safety performance outcomes and, therefore, the commercial benefits of responsibility management in the context of SCM remain open for interrogation. This study aims to explore the impact of responsible supply chain management behaviors on social performance among pharmaceutical companies in China. And also, investigate the intervening roles of process innovation (PI) and supply chain integration (SCI) as mediating and moderating constructs, respectively. The research hypothesis was formulated following an extensive study of relevant literature and was based on resource and capability-based theories such as the resource-based view, the natural resource-based view, and the stakeholder theories. The design of the study was descriptive with a confirmatory reach, applied to 123 Chinese pharmaceutical firms selected across Jiangsu, Shanghai, Zhejiang, and Guangdong provinces. The proposed theoretical model was tested using partial least squares structural equation modeling (PLS-SEM). The empirical findings of the study confirmed that a practical application of RSCM behaviors, process innovation, and supply chain integration initiatives positively and significantly improves social performance outcomes. This confirms the position of existing literature that there is a positive relationship between RSCM behaviors and social performance. It also validated the belief that process innovation and supply chain integration positively mediates and moderates the relationship between RSCM and social performance, respectively. Therefore, the findings herein can be considered as complementary to the existing body of knowledge in the field. The practical implications derived from this study will contribute to sustainable development and expand knowledge both in industry and in academia.
\end{abstract}

Keywords : Responsible Supply Chain Management (RSCM); Process innovation; Supply Chain Integration Chinese Pharmaceutical Industry; Social Performance; Structural Equation Modelling (SEM).

\section{INTRODUCTION}

This last phase of the analysis chapters is to solicit empirical evidence to support the argument that by and large when an organization applied responsible supply chain management practices, it can secure substantial social performance. As indicated in earlier 
section of the study, social performance relates to the principles, practices, and outcomes of firms' relationships with people organizations, institutions, societies, and the environment relative to the deliberate actions of businesses toward its stakeholders and other unintended externalities of the business activity. Kassinis and Soteriou (2015), as well as Gimenez et al. (2012), provide the strongest indicators of social performance. In their studies, the authors explain that when organizations voluntarily commit to incorporate account social and environmental considerations to manage their relationships with stakeholders, such an initiative tends to reduce the impacts and risks of their operations to the general public and helps to improve occupational health and safety of employees. Further Gimenez et al. (2012) asserts that firms' decision to highlights the management of environmental, social and economic impacts and the encouragement of good governance practices, throughout the lifecycles of goods and services helps them to provide more positions in community, improve product image, improve firm's image in the eyes of customers and further improve firm's social reputation. The empirical literature has already made groundbreaking findings in some of these areas, but the generalizability of these findings are still disputable, as few studies have occurred in the healthcare sector in general and the pharmaceutical industry in particular. This is mainly because social performance has not been an essential factor in evaluating business success in China until the advent of sustainability and corporate social responsibility. The social contract theory provides a stronger basis for this study to explore the interaction between responsible supply chain and social performance. The theory posits that business organizations are corporate legal entities that live in a society with other people under the control of an authority. Thus to survive and prosper, each individual, including corporate legal entities, must pursue the common interest of society by following agreed norms and social mores (moral and legal) in exchange for the protection of the society. Thus even though an organization may be profit-oriented, it must be guided by the need to protect other members of the society and act within the framework of governance to maintain social harmony, which is the precursor for its eventual success in the society. Based on the above importance of the social performance and contribution of an organization, it is hypothesized that;

- H3a: There is a direct relationship between RSCM behaviors and firms' social performance

- H3b: Process innovation significantly mediates the relationship between RSCM and social performance

- H3c: Supply Chain Integration significantly moderates the relationship between RSCM behaviors and social performance.

Figure 1 shows the diagrammatic representation of the framework for this section of the analysis of data

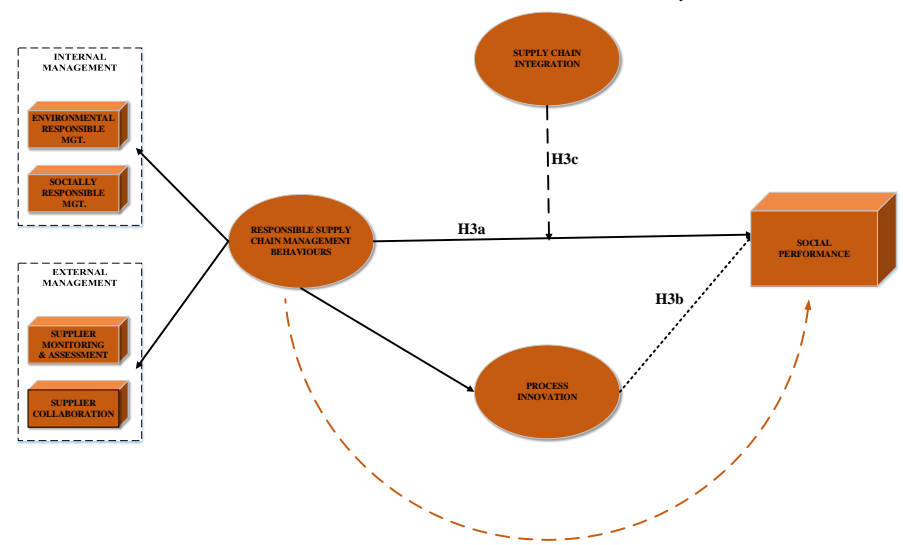

Figure 1 : Effect of RSCM, Process Innovation, SCI on Social Performance

\section{METHODOLOGY}

The study explored different analytical models to identify the influence of responsible supply chain management behaviors on social performance. A five-point scale closed-ended questionnaire was used to calibrate the constructs of the social performance, 
responsible supply chain, and the moderating factor (supply chain integration) as well as the mediating factor (process innovation). Unlike the previous constructs, the analysis was interested in the differences between the internal and external factors that influence responsible supply chain management. Thus the internal supply chain factors were environmental management (eco-design, sustainable packaging, and environmental protection management) and socially responsible management (human rights, philanthropy, and safety). The studies of Carter et al., Zhu et al. (2005), Carter and Jennings (2002), Emmelhainz and Adams (1999), Zhu et al. (2005), Zsidisin and Hendrick (1998), Dang and Chu (2016), Zailani et al. (2012), Wantao Yu et al. (2014) provided the basis for this calibration. In total internal responsible supply chain factors had 21 questions within its categories, whereas the external factors had 17 questions within its constructs. The other components of the scale, namely, supply chain integration and process innovation, remained the same in the analysis. Thus they were both measured by the set of questions proposed in Salerno et al., 2015 (fast response to the new processes introduced by other companies within the same sector, pioneering disposition to introduced new process and number of changes in the process within the last one year). Supply chain integration was measured by supplier integration, customer integration, and internal integration. A total of 122 responses were validated for the analysis in this area of the study based on the accuracy of the responses that were collected from the respondents. Firstly descriptive statistics were used to explore the relationships between the variables. Using Chi-Square tests, the difference of means of external environmental factors and internal environmental factors were used to examine the significance of the difference between external and internal factors and their respective effect on the responsible supply chain. Subsequently, the Warp PLS analytical tool was used to extract inferential statistics including factor analysis

\section{RESULTS}

\subsection{Descriptive Statistics}

Table 1 : Summary of Construct Descriptive



** Correlation is significant at the 0.01 level (2-tailed) at the diagonal 
* Correlation is significant at the 0.05 level (2-tailed)

Table 1 explored the descriptive statistics of the constructs as well as the degree of multicolinearity among the variables. For the mean response values, the analysis indicates that external factors had a means response value of 4.3 with a standard deviation of 0.04 , whereas the internal factors also had a means response value of 3.8 with a standard deviation of 0.25 . In both cases, the skewness and kurtosis values were within acceptable range of normal distribution. The analysis of the distribution of the responsible supply chain management, which is a composite value, shows a mean response value of 4.1 with a standard deviation of 0.27 . In the case also, the skewness and the kurtosis values are within an acceptable range and indicate normality of distribution. Regarding the descriptive statistics of the supply chain integration attributes, the composite mean value of supplier integration, customer integration, and internal integration is 31 , with a standard deviation of 0.56 . The skewness and kurtosis values were observed to lie within an appropriate range of normal distribution. Process innovation is the next most crucial factor that was explored based on descriptive statistics and variability. The results show a composite score of 4.2 with a standard deviation of 0.34 . Social performance, on the other hand, recorded a composite score value of 3.8 with a standard deviation of 0.27 . Again the skewness and kurtosis were within acceptable ranges. The next issue the table reveals is the analysis of the correlation coefficients between the variables, which is an indicator of the degree of multicolinearity among the variables. According to Pallant (2006), there should be a lower correlation since each independent variable must be truly independent of each other. The threshold of this is for the Pearson product moment $r$ value to be lower than 0.5 in each case. The analyzed information supports the low level of multicolinearity among the variables. In the specific case, it is noted that the highest level of colinearity (0.35) is between supply chain Integration and internal factors, and this is lower than the recommended threshold.

\subsection{Reliability and Validity Test}

Confirmatory factor analysis (CFA) was adopted to assess the measurement components adequacy, and we also examined the reliability and validity of the constructs, which showed the item-to total correlations were stronger. Some scholars have argued that factor loadings from .50 should be an acceptable loading. For this reason, the constructs that reported standardized factor loadings above the .50 criteria were accepted as recommended by Hair et al. (2010), who posited that each item is considered a satisfactory item when item loadings are greater than 0.50. In all, the measures of the study were considered as showing a reliability that is satisfactory. High average variance extracted (AVE) was demonstrated for all constructs, which provided strong evidence of convergent validity. The results of CFA, reliability, and convergent validity are shown in Table 2

\subsection{EFA, Reliability and Validity Index}

Table 2 : Factor Loadings and Goodness of Fit

\begin{tabular}{|l|l|l|l|l|}
\hline VARIABLE & $\boldsymbol{\alpha}$ & CR & AVE & $\begin{array}{l}\text { FACTOR } \\
\text { LOADING }\end{array}$ \\
\hline $\begin{array}{l}\text { RESPONSIBLE } \\
\text { SUPPLY } \\
\text { CHAIN }\end{array}$ & $\mathbf{0 . 8 7 5}$ & $\mathbf{0 . 6 6 0}$ & $\mathbf{0 . 8 9 2}$ & \\
\hline Internal Factors & $\mathbf{0 . 7 5 5}$ & $\mathbf{0 . 8 8 3}$ & $\mathbf{0 . 7 1 6}$ & 0.897 \\
\hline INF1 & & & & 0.856 \\
\hline INF2 & & & & 0.886 \\
\hline INF3 & & & & 0.750 \\
\hline INF4 & & & & 0.732 \\
\hline INF5 & & & & 0.827 \\
\hline INF6 & & & & 0.847 \\
\hline SRM4 & & & & 0.820 \\
\hline SRM5 & & & & 0.779 \\
\hline
\end{tabular}




\begin{tabular}{|l|l|l|l|l|}
\hline External Factors & $\mathbf{0 . 8 7 1}$ & $\mathbf{0 . 9 0 1}$ & $\mathbf{0 . 6 9 1}$ & 0.924 \\
\hline EXT1 & & & & 0.818 \\
\hline EXT2 Chain & $\mathbf{0 . 7 5 6}$ & $\mathbf{0 . 8 6 8}$ & $\mathbf{0 . 7 2 9}$ & \\
\hline $\begin{array}{l}\text { Supply } \\
\text { Integration }\end{array}$ & & & & 0.753 \\
\hline SCI1 & & & & 0.865 \\
\hline SCI2 & & & & 0.886 \\
\hline SCI3 & $\mathbf{0 . 8 7 5}$ & $\mathbf{0 . 8 9 2}$ & $\mathbf{0 . 6 6 0}$ & \\
\hline $\begin{array}{l}\text { Process } \\
\text { Innovation }\end{array}$ & & & & 0.732 \\
\hline PI1 & & & & 0.847 \\
\hline PI2 & $\mathbf{0 .}$ & $\mathbf{0 . 8 1 4}$ & $\mathbf{0 . 5 5 9}$ & \\
\hline PI3 & $\mathbf{7 6 3}$ & & & 0.733 \\
\hline $\begin{array}{l}\text { Social } \\
\text { Performance }\end{array}$ & & & & 0.750 \\
\hline SP1 & & & & 0.820 \\
\hline SP2 & & & & 0.808 \\
\hline SP3 & & & 0.7405 \\
\hline SP4 & & &
\end{tabular}

groups (Brown, 2014). The use of Confirmatory Factor Analysis (CFA) continues to gain ground in the social science literature as a result of the belief researchers have in the Structural Equation Model as a robust model specifically. Given the key impact CFA makes in the measure development and due to the understanding that having a tool that manages the measurement of variables effectively, it can be presumed to be paramount quantitatively simply because its role is crucial to the results a researcher reports. We sought to find out the relationship between the latent variables using Warp PLS. The model consisted of the latent variables responsible supply chain management (internal and external factors), supply chain integration (supplier integration, customer integration, and internal integration), process innovation, and social performance. The items in the observed variables with low factor loadings were eliminated, leaving the strong ones to be included, and the final acceptable loadings are presented in table 7.2. The information in the table

\subsection{Confirmatory Factor Analysis}

Existing social science research studies approves of the use of confirmatory factor analysis (CFA) as a statistical tool for probing the nature of and relationships among latent constructs. This is because the confirmatory factor analysis helps to measure the construct validity, identify method effects, and helps shows adequacy an indication of a good fit for the data. External factors and internal factors were treated as second order constructs to obtain the following fit indices. There was $(\chi 2=1138.516, \mathrm{df}=407$, $\chi 2 / \mathrm{df}=2.797, \mathrm{TLI}=.957, \mathrm{CFI}=.986, \mathrm{GFI}=.961, \mathrm{IFI}=.977$, $\mathrm{RMSEA}=.048$. Figure 2 shows the final path analysis of the relationship between the variables.

Table 3 : Path Analysis

\begin{tabular}{lllllll}
\hline Parameter & & & Coefficient & Lower & Upper \\
\hline RSCM & $<---$ & INT & 0.708 & 0.116 & 0.343 & 0.054 \\
RSCM & $<---$ & EXT & 0.417 & 0.322 & 0.780 & 0.035 \\
SP & $<---$ & RSCM & 0.309 & 0.048 & 0.069 & 0.013 \\
PI & $<---$ & RSCM & 0.485 & 0.082 & 0.045 & 0.034 \\
EP <--- & PI <--- & RSCM & 0.027 & 0.082 & 0.045 & 0.024 \\
EP <--- & SCI <--- & RSCM & 0.080 & 0.158 & 0.025 & 0.068 \\
\hline
\end{tabular}




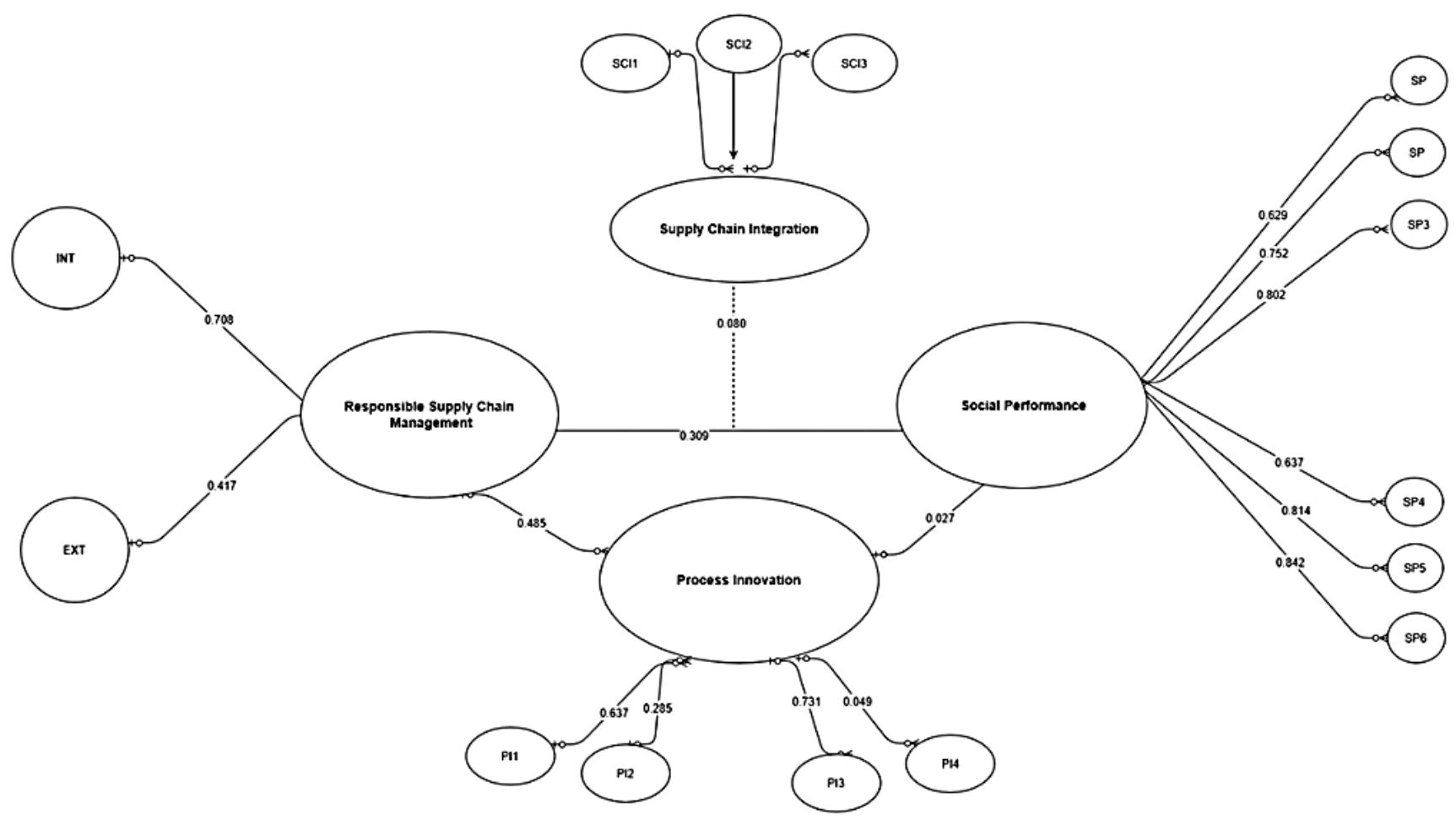

Figure 2 : Path Diagram of the Relationship among the Variables

Figure 2 presents the final path analysis of the relationships among the designated variables. Firstly the study indicated that internal management such as safety, philanthropy, human rights, environmental protection management, sustainable packaging, and eco-design significantly influenced responsible supply chain than the external factors. The regression coefficient of the effect of the internal factors is 0.708 , and this is statistically significant at a $95 \%$ confidence interval. On the other hand, the influence of external management factors, namely; supplier monitoring \& assessment and supplier collaboration, recorded a regression coefficient value of 0.417 and a sig. value of 0.035 .

Regarding the influence of responsible supply chain management on social performance, the study recorded a regression coefficient value of 0.309 and a significant value of 0.309 . The trend is similar to the case of the influence of responsible supply chain management on process innovation that recorded a regression coefficient value of 0.485 with a significant value of 0.045 . In both instances, the analysis indicates strong statistical significant at a $95 \%$ confidence interval. The mediating influence of process innovation in the relationship between responsible supply chain management and social performance is evident in the relationship between process innovation and social performance. The regression coefficient of 0.027 reduces the direct influence from 0.309 , which is an indication of the presence of a partial mediation role between the variables. Finally, the moderating effect of supply chain integration in the interplay between responsible supply chain and social performance is tested to be statistically significant based on the regression coefficient of 0.080 .

\section{SUMMARY}

The objective of this chapter was to highlight the extent to which responsible supply chain management can influence a firm's social performance. The study analyzed data from selected 
respondents drawn from the pharmaceutical manufacturing sub-sector in China to draw appropriate conclusions. The study validated the hypotheses that were outlined to be tested direct relationship exist between RSCM behaviors, and firms' social performance was validated found to be statistically significant at a $95 \%$ confidence interval. Firstly, hypothesis 1 that a direct relationship exists between responsible supply chain and social performance of a firm is affirmed, the study further noted that by and large the internal supply chain management factors were of greater importance in the valuing responsible supply chain management activities. This implies that managers ought to give enough time, resource, and attention to understanding the intricate issues involved in stimulating greater responsible supply chain management. Further, evidence is adduced from the analyzed data to indicate that at $95 \%$ confidence interval process innovation significantly mediates the relationship between RSCM and social performance. With a 95\% confidence, it can be inferred from this analysis that supply chain integration significantly moderates the relationship between responsible supply chain management behaviors and social performance.

\section{REFERENCES}

[1]. Carter, C.R. and Jennings, M.M. (2002), "Logistics social responsibility: an integrative framework", Journal of Business Logistics, Vol. 23 No. 1, pp. 145180.

[2]. Dang, S. and Chu, L. (2016), "Evaluation framework and verification for sustainable container management as reusable packaging", Journal of Business Research, Vol. 69 No. 5, pp. 1949-1955.

[3]. Emmelhainz, M.A. and Adams, R.J. (1999), "The apparel industry response to 'sweat-shop' concerns: a review and analysis of codes of conduct", Journal of Supply Chain Management, Vol. 35 No. 3, pp. 51-57.
[4]. Emmelhainz, M.A. and Adams, R.J. (1999), "The apparel industry response to 'sweat-shop' concerns: a review and analysis of codes of conduct", Journal of Supply Chain Management, Vol. 35 No. 3,

[5]. Gimenez, C., Sierra, V. and Rodon, J. (2012), "Sustainable operations: their impact on the triple bottom line", International Journal of Production Economics, Vol. 140 No. 1, pp. 149-159. pp. 51-57.

[6]. Kassinis, G.I and Soteriou, A.C, (2015) Environmental and quality practices: using a video method to explore their relationship with customer satisfaction in the hotel industry. Operations Management Research.

[7]. Wantao, Y., Chavez, R., Feng, M. and Wiengarten, F. (2014), "Integrated green supply chain management and operational performance", Supply Chain Management: An International Journal, Vol. 19 Nos 5/6, pp. 683-696.

[8]. Zailani, S., Jeyaraman, K., Vengadasan, G. and Premkumar, R. (2012), "Sustainable supply chain management in Malaysia: a survey", International Journal of Production Economics, Vol. 140 No. 1, pp. 330-340.

[9]. Zhu, Q., Sarkis, J. and Geng, Y. (2005), "Green supply chain management in China: pressures, practices and performance", International Journal of Operations and Production Management, Vol. 25 No. 5, pp. 449-468.

[10]. Zsidisin, G.A. and Hendrick, T.E. (1998), "Purchasing's involvement in environmental issues:

[11]. A multi-country perspective”, Industrial Management and Data Systems, Vol. 98 No. 7, pp. 313-320

Cite this article as : Maxwell Opuni Antwi, Lulin Zhou, Charles Kwarteng Antwi, "Analysis of the Relationship between Responsible Supply Chain Management and Social Performance", International Journal of Scientific Research in Science and Technology (IJSRST), Online ISSN : 2395-602X, Print ISSN : 2395-6011, Volume 7 Issue 2, pp. 169-175, March-April 2020. Available at doi : https://doi.org/10.32628/IJSRST207214 Journal URL : http://ijsrst.com/IJSRST207214 